\title{
As Geometrias Esférica e Hiperbólica em Foco: sobre a Apresentação de alguns de seus Conceitos Elementares a Estudantes do Ensino Médio
}

\author{
Wanderley Pivatto Brum* \\ Elcio Schuhmacher ${ }^{* *}$ \\ Sani de Carvalho Rutz da Silva**
}

Tradicionalmente, os conhecimentos geométricos abordados em sala de aula se restringem às relações lógicas e construções de símbolos advindos de uma Geometria dedutiva e axiomática, estabelecida na Grécia há cerca de 2700 anos e conhecida, hoje, como Geometria Euclidiana. No entanto, ao observar a superfície terrestre com sua forma elipsoidal, as montanhas, as ondas do mar e tantos outros objetos encontrados na natureza, evidenciam-se as dificuldades de construir alguns conceitos no campo da Geometria sustentados por noções primitivas como de reta, ponto e plano.

Nas duas últimas décadas, houve uma intensa discussão nos meios educacionais por parte de pesquisadores como, por exemplo, Kalleff (2004), Cabariti (2006), Alves (2008), Bongiovani (2010), Carvalho e Carvalho (2011), Cedrez (2012), Leivas (2012) e Martos (2012) sobre a inclusão, nos bancos escolares, de conteúdos advindos da Geometria não Euclidiana, como as Geometrias Esférica e Hiperbólica, considerados adequados à formação de estudantes para o século XXI, em decorrência dos avanços teóricos da Matemática e da Computação.

Dessas discussões emergiram alguns questionamentos: o ensino da Geometria não Euclidiana é um tema distante da realidade dos estudantes? O modelo geométrico para representar o planeta Terra abordado nas aulas de Geografia e Matemática é um plano, uma

\footnotetext{
* Doutorando em Ensino de Ciência e Tecnologia pela Universidade Tecnológica Federal do Paraná (UTFPR). Professor da Faculdade Avantis de Ensino em Balneário Camboríu, Santa Catarina, Brasil. Endereço: Rua Antônio da Veiga, 140, Victor Konder, 89012-900, Blumenau, Santa Catarina, Brasil. E-mail: ufsc2013@yahoo.com.br

** Doutor em Química pela Universidade Federal de Santa Catarina (UFSC). Professor da Universidade Regional de Blumenau (FURB), Santa Catarina, Brasil. Endereço: Rua Antônio da Veiga, 140, Victor Konder, $89012-$ 900, Blumenau, Santa Catarina, Brasil. E-mail: elcio@ furb.br

Doutora em Ciência dos Materiais pela Universidade Federal do Rio Grande do Sul. Professora da Universidade Tecnológica Federal do Paraná (UTFPR), Ponta Grossa, Paraná, Brasil. Endereço: Av. Monteiro Lobato, Km 04, CEP: 84016-210, Ponta Grossa-Paraná, Fone: +55 (42) 3235-7012. E-mail: sani@utfpr.edu.br
} 
folha retangular ou uma superfície quase esférica? Se um dos pontos de discussão é a reformulação do ensino no Brasil, por que as Geometrias não Euclidianas ainda não são consideradas, pelos professores? O ensino de Geometrias não Euclidianas, como a Esférica e Hiperbólica, vem causando inquietações em professores de Matemática por ser um assunto novo e ainda desconhecido?

A busca de respostas para essas questões revela, além de sua importância, a necessidade de divulgação, junto aos professores, desses conteúdos ainda pouco explorados em sala de aula, afinal, nos dias atuais, naves espaciais, por exemplo, percorrem em suas viagens trajetórias que não são retilíneas e, no passado, segundo Eves (2008), Boyer (2009) e Mlodinow (2010), existem registros que indicam o medo de alguns navegadores por acreditarem que, ao fim do horizonte, navios eram engolidos ou se chegaria ao fim do mundo devido ao modo de conceber o formato da Terra. É possível encontrar, ainda, alguns estudantes que representam geometricamente o planeta de modo euclidiano e não é difícil comprovar tal afirmação, basta observar que ao demonstrar o comportamento da gravidade sobre os seres humanos, evidenciam-se modelos euclidianos em detrimento de modelos esféricos, hiperbólicos e até elipsóidicos.

\section{Os Parâmetros Curriculares Nacionais (PCN) e o ensino de outros sistemas geométricos}

A Geometria é um tema interessante para ser explorado pelos professores devido à riqueza das ilustrações, por possibilitar resoluções diversas com criatividade e, por fim, proporcionar aos estudantes uma interação mais dinâmica com o conhecimento. Uma das justificativas para essa afirmação é a existência de discussões acerca da inserção das Geometrias Esférica e Hiperbólica nos currículos escolares que se encontram nos Parâmetros Curriculares Nacionais de Matemática (BRASIL, 1998):

[...] a Matemática não evolui de forma linear e logicamente organizada. Desenvolve-
se com movimentos de idas e vindas, com rupturas de paradigmas. Frequentemente
um conhecimento é amplamente utilizado na ciência ou na tecnologia antes de ser
incorporado a um dos sistemas lógicos formais do corpo da Matemática. Exemplos
desse fato podem ser encontrados no surgimento dos números negativos, irracionais
e imaginários. Uma instância importante de mudança de paradigma ocorreu quando
se superou a visão de uma única geometria do real, a Geometria Euclidiana, para
aceitação de uma pluralidade de modelos geométricos, logicamente consistentes,
que podem modelar a realidade do espaço físico. (BRASIL, 1998, p. 24, grifo
nosso).

Por vezes, a concepção linear faz com que, ao se definir qual será o elo inicial da cadeia, tomem-se os chamados fundamentos como ponto de partida. É o que ocorre, por 
exemplo, quando se privilegiam as noções de ponto, reta e plano como referência inicial para o ensino de Geometria, ou quando se tomam os conjuntos como base para a aprendizagem de números e operações, caminhos que não são, necessariamente, os mais adequados à compreensão de conceitos inerentes à Geometria não Euclidiana. O que também se observa em termos escolares é que, muitas vezes, os conteúdos geométricos são tratados isoladamente, apresentados e exauridos num único momento. Quando acontece de serem retomados (geralmente num mesmo nível de aprofundamento, apoiando-se nos mesmos recursos), é apenas com a perspectiva de utilizá-los como ferramentas para a aprendizagem de novas noções e não para possibilitar a inserção de novas ideias.

Nesse sentido, os PCN (Parâmetros Curriculares Nacionais) afirmam que entre os objetivos do ensino de Matemática se encontra o desenvolvimento do pensamento geométrico. Recomenda-se a exploração de situações de aprendizagem que levem o estudante a resolver situações problema de localização e deslocamento de pontos no espaço, ler mapas, estimar e comparar distâncias percorridas, reconhecer propriedades de formas geométricas e saber usar diferentes unidades de medida. Portanto, há uma orientação para situações de aprendizagem que levem o estudante a estabelecer diferenças entre objetos sob diferentes pontos de vista, construindo e interpretando suas representações.

Para estabelecer diferenças entre objetos geométricos, conforme orientam os PCN, é preciso identificar uma pluralidade de modelos geométricos na natureza, o que pode ser feito pelo estudo das navegações; usando o sistema de localização por GPS (Sistema de Posicionamento Global); em aulas de Geografia, ao tratar sobre o planeta Terra; na Física, ao abordar o comportamento da luz no espaço; a partir de objetos comuns do nosso cotidiano, como trompetes, batatas enlatadas, cornetas, ondas do mar, poltronas, garrafas de vinhos entre outros.

Com tantas possibilidades citadas, e sabendo de diversas pesquisas já realizadas nesse domínio, por que grande parte dos currículos escolares ainda se pauta, exclusivamente, em conhecimentos euclidianos? Essa pergunta promove discussões entre pesquisadores, como Kalleff (2004) e Cabariti (2006). No entanto, uma apresentação de situações cujas resoluções necessitem de conhecimentos geométricos esféricos e hiperbólicos, a partir de um resgate histórico, mobiliza materiais potenciais para o objetivo ao qual este trabalho se dispõe: uma aprendizagem significativa sobre as Geometrias Esférica e Hiperbólica no Ensino Médio.

Para Coutinho (2001), a abordagem de outras geometrias em sala de aula, conforme orientações dos PCN, possibilita relacionar a Geometria a um campo atual e ativo de pesquisa científica que vai além das ideias apresentadas por Euclides. Nessa direção, é preciso uma 
compreensão por parte dos professores e pesquisadores de que a Geometria Euclidiana não é a única possível, praticável no mundo, que solucionará todos os problemas no cotidiano e do mundo cientifico.

\section{Alguns problemas que impedem a inserção efetiva de conteúdos de geometria esférica e hiperbólica no ensino médio}

A Geometria é considerada um dos alicerces da Matemática, devido à sua importância em diversas áreas do conhecimento, passando a ser compreendida como uma ciência do pensamento (LEIVAS, 2012; BONGIOVANI, 2010). Porém, como é abordada na maioria das escolas, atualmente, por meio de problemas descontextualizados, por métodos de repetição sem relacionar com o cotidiano do estudante, parece não ser de grande interesse para os estudantes. Nessa direção, há uma tendência de muitos professores e estudantes a passarem a valorizar regras e exemplos de procedimentos para serem utilizados em problemas que, em geral, são descontextualizados. Para Coll, Marchesi e Palácios (2007), a aprendizagem repetitiva não busca relacionar os conhecimentos prévios com o novo conteúdo apresentado.

A ausência de uma abordagem sobre as Geometrias Esférica e Hiperbólica no Ensino Médio mostra que a maioria dos professores de Matemática desconsidera os conhecimentos cotidianos dos estudantes ou, como afirma Demo (2012), que se segue a metodologia de um determinado livro didático como fonte única de conhecimento, o que evidencia uma fragilidade de um sistema de ensino que privilegia resultados obtidos de modo mecânico e sem relação com o cotidiano.

Chassot (2011) afirma que a luta é para tornar o ensino menos asséptico, menos peremptório, menos abstrato, menos a-histórico e menos ferreteador. Por se tratar de um assunto pouco conhecido entre a maioria dos professores do Ensino Médio, alguns fatores inviabilizam a introdução das Geometrias Esférica e Hiperbólica no ensino escolar, entre eles a complexidade matemática exigida por esse tema, tornando essa área bastante técnica até mesmo no meio universitário. No entanto, muitos conteúdos, como números complexos, polinômios e Geometria Analítica, já foram considerados de difícil abordagem na escola e atualmente constam, sem qualquer questionamento, dos programas de cursos de Matemática.

Apesar de sua reconhecida importância, por que a Geometria é deixada em segundo plano ou é, muitas vezes, desprezada pelos professores? Uma possível resposta está na promulgação da primeira LDB (Lei de Diretrizes e Bases do Ensino) de $1^{\circ}$ e $2^{\circ}$ Graus, de 1961, que possibilitou a cada professor elaborar seu programa de acordo com as necessidades 
dos estudantes. É possível que uma formação inicial deficitária de diversos professores acerca dos conhecimentos de outras Geometrias também seja um indicativo para ausência desse tema em sala de aula.

O fato é que muitos professores se tornaram dependentes dos livros didáticos, que enfatizam conteúdos algébricos em detrimento dos geométricos. Para Vogelmann (2011), a maioria dos professores e dos livros didáticos formam um pacto que privilegia a Aritmética e a Álgebra, deixando a Geometria em segundo plano.

Para Almouloud (2004), apesar de as Geometrias Esférica e Hiperbólica serem um ramo importante da Matemática, por servir principalmente de instrumento para diversas áreas do conhecimento, existem, atualmente, problemas relacionados ao seu ensino, caracterizados pela falta de correlação com outras áreas do conhecimento, o que impede uma visão mais ampla e crítica por parte do estudante. Por outro lado, é preciso lembrar que muito se tem discutido e pesquisado sobre o ensino de Geometria na Educação Básica. Existe um excesso de formalismo com a prevalência das demonstrações geométricas euclidianas e o abandono por completo de outras Geometrias em sala de aula.

\section{Algumas justificativas para apresentação de conceitos elementares de geometria esférica e hiperbólica no ensino médio}

Atualmente, os conteúdos geométricos ensinados nas escolas possibilitam a resolução de problemas para superfícies planas, por exemplo, quadrado, retângulo, triângulo, círculos e para sólidos de revolução como cone, cilindro e esfera. Contudo, existem objetos que se encontram na natureza que exigem conhecimentos que transcendem a Geometria Euclidiana.

Para Postman (2002), mesmo os conhecimentos que estão corretos e parecem não precisar de emenda, estão limitados em seu alcance e em sua aplicabilidade. Por exemplo, é possível citar o caso de um triângulo que em um plano possui invariavelmente uma soma de $180^{\circ}$ para seus ângulos internos o que, porém, não se mantém em uma superfície curva. Dessa maneira, os conhecimentos geométricos organizados por Euclides são limitados no sentido de explicar determinadas situações no campo da Geometria.

Um dos pontos mais notáveis para a aplicação de conhecimentos geométricos não euclidianos é a prática da navegação, em que certamente a curvatura da Terra não pode ser desprezada. Ainda existem pessoas com a sensação de que um navio, ao realizar determinada viagem entre dois países, seguirá uma trajetória em linha reta. Contudo, por acompanhar a 
curvatura da Terra, o caminho descrito será o de um arco, demonstrando que a menor distância entre dois pontos pode não ser um segmento de reta.

Pelo fato de a Geometria Euclidiana não ser a única aplicável a situações do cotidiano, talvez seja coerente, segundo Paty (2012) e Cedrez (2012), pensar que as diferentes geometrias ocupem lugares próprios no universo matemático, e se constituam instrumentos de conhecimento ajustados a determinados problemas. Dessa maneira, é impossível elencar qual delas é a melhor ou mais útil, mas é possível definir qual delas deve ser explorada. Por exemplo, os conhecimentos euclidianos são adequados ao trabalho do pedreiro, que utiliza instrumentos como régua e esquadro para realizar marcações e delimitar áreas de construção, o que não ocorre com um marinheiro ou um piloto de avião, que realizam viagens entre dois países.

Com relação à sua aplicação em sala de aula, o ensino das Geometrias Esférica e Hiperbólica já se manifesta em algumas propostas curriculares brasileiras (SÃO PAULO, 1991; CURITIBA, 1988) que sugerem o ensino da Geometria Esférica para “[...] concretizar as noções de círculos máximos e circunferências máximas, respectivamente, em esferas e superfícies esféricas [...]”"

Contudo, discussões sobre o ensino de noções básicas das Geometrias Esférica e Hiperbólica ainda ocorrem nas escolas da rede pública de muitos estados brasileiros, possivelmente pela dificuldade de sua compreensão por parte de alguns professores, pelo desconhecimento de linhas metodológicas adequadas ou, ainda, pela ausência de textos nos livros didáticos que contemplem o assunto.

Sob o olhar da aprendizagem de Geometria, os estudantes, em geral, têm acentuadas dificuldades em resolver problemas que transitam no campo dos conceitos geométricos. As fragilidades que os estudantes evidenciam na interpretação e solução de situações do cotidiano nos quais são necessários conhecimentos geométricos, é um dos grandes desafios enfrentados pelos professores. Uma abordagem às Geometrias Esférica e Hiperbólica, por meio de diferentes atividades, é uma possibilidade para o estudante realizar uma leitura do mundo mais concisa e universal.

\section{Considerações}

A Matemática desenvolveu-se seguindo caminhos diferentes nas mais diversas culturas. O modelo de Geometria, hoje mais utilizado nas escolas, originou-se com a civilização grega, no período que vai aproximadamente de 700 a.C. a 300 d.C., permitindo a 
criação de sistemas formais, logicamente estruturados a partir de um conjunto de premissas e empregando regras de raciocínio preestabelecidas. A maturidade desses sistemas formais foi atingida no século XIX, com o surgimento de Geometrias não Euclidianas, dentre as quais a Esférica e a Hiperbólica.

Os conceitos elementares de Geometria constituem parte importante do currículo de Matemática no Ensino Médio, porque, por meio deles, o estudante desenvolve um tipo especial de pensamento que permite compreender, descrever e representar, de forma organizada, o mundo em que vive. Mendes (2001) afirma que por meio do conhecimento geométrico não euclidiano, o estudante é capaz de pensar e compreender as leis matemáticas a partir de certas propriedades e artifícios usados hoje, mas difíceis de descobrir em períodos anteriores ao que vivemos. O trabalho com conceitos elementares no campo das Geometrias Esférica e Hiperbólica busca contribuir, também, para a aprendizagem de números e medidas, pois estimula o estudante a observar, perceber semelhanças e diferenças, identificar regularidades etc.

A investigação do espaço esférico e hiperbólico por parte do professor pressupõe a exploração de situações em que sejam necessárias algumas construções geométricas com régua e compasso, como visualização e aplicação de propriedades das figuras, além da construção de outras relações. Este amálgama de conteúdos, ainda pouco explorado na escola, contempla não apenas o estudo das formas, mas também as noções relativas à posição, à localização de figuras e aos deslocamentos no plano e sistemas de coordenadas.

Deve-se destacar, também, a importância das transformações geométricas (isometrias, homotetias) nesses modelos geométricos, de modo a permitir o desenvolvimento de habilidades de percepção espacial e, como recurso, para induzir de forma experimental a descoberta, por exemplo, das condições para que duas figuras sejam congruentes ou semelhantes. Além disso, o espaço deve ser explorado a partir de objetos do mundo físico, de obras de arte, pinturas, desenhos, esculturas e artesanato, de modo que permita ao estudante estabelecer conexões entre as Geometrias Esférica e Hiperbólica com outras áreas do conhecimento.

\section{Referências}

ALMOULOUD, S. A. A geometria no ensino fundamental: reflexões sobre uma experiência de formação envolvendo professores e alunos. Revista Brasileira de Educação, São Paulo, n. 27, p. 94 108, Set /Out /Nov /Dez 2004. 
ALVES, S. Geometria Não Euclidiana. São Paulo: IME-USP: material para oficina; Semana da Licenciatura, 2008.

BOYER, C. B. História da Matemática. 2a . ed. São Paulo: Blücher, 2009.

BONGIOVANI, V. De Euclides às geometrias não euclidianas. Revista Iberoamericana de Educación Matemática. São Paulo, v.1, n. 22, p. 37-51, 2010.

BRASIL. Secretaria de Educação Fundamental. Parâmetros curriculares nacionais: matemática. Brasília: MEC/SEF, 1998.

CABARITI, E. A geometria hiperbólica na formação docente: possibilidades de uma proposta com o auxílio do cabri-géomètre. III Seminário Internacional de Pesquisa em Educação Matemática, 2006, São Paulo.

CARVALHO, M. A. S.; CARVALHO, A. M. F. T. C. O ensino de geometria não euclidiana na educação básica. XIII Conferência Interamericana de Educação Matemática, 2011, Recife.

CEDREZ, A. J. P. Construcción, necessidad e intuición de essência em geometria. Scientia \& Studia. São Paulo, v. 7, n. 4, p. 595-617, 2012.

CHASSOT, A. A alfabetização científica: questões e desafios para a educação. Ijuí: Unijuí, 2011.

COLL, C.; MARCHESI, A.; PALACIOS, J. Desenvolvimento psicológico e educação: psicologia da educação escolar. $2^{\mathrm{a}}$. ed. Porto Alegre: Artmed, 2007.

COUTINHO, L. Convite às Geometrias Não Euclidianas. 2a ${ }^{\mathrm{a}}$ ed. Rio de Janeiro: Interciência, 2001.

CURITIBA. Secretaria Municipal de Educação. Currículo básico: uma contribuição para a escola pública brasileira. Imprensa Oficial do Estado Paraná, 1988.

DEMO, P. O mais importante da educação importante. São Paulo: Atlas, 2012.

EVES, H. Introdução à história da Matemática. São Paulo: Unicamp, 2008.

KALLEFF, A. M. Desenvolvimento de Atividades Introdutórias ao Estudo das Geometrias não Euclidianas: Atividades Interdisciplinares para Sala de Aula e Museus Interativos. Congresso Brasileiro de Extensão Universitária, n. 2, 2004. Belo Horizonte.

LEIVAS, J. C. P. Educação geométrica: reflexões sobre ensino e aprendizagem em geometria. Revista SBEM-RS, Porto Alegre, n. 13, v.1, p. 9-16, 2012.

MARTOS, Z. G. Geometrias não euclidianas: uma proposta metodológica para o ensino de Geometria no Ensino Fundamental. 143f. Dissertação (Mestrado em Educação Matemática) - Instituto de Geociências e Ciências exatas, Universidade Estadual Paulista, Rio Claro, 2012.

MENDES, I. A. O uso da história da matemática: reflexões teóricas e experiências. Belém EDUEPA, 2001. 90 p.

MLODINOW, L. A janela de Euclides: a história da geometria, das linhas paralelas ao hiperespaço. São Paulo: Geração, 2010.

POSTMAN, N. O fim da educação: redefinindo o valor da escola. Rio de Janeiro: Graphia, 2002. 
PATY, M. O estilo cientifico de Einstein na exploração do domínio quântico: uma visão da relação entre a teoria e seu objeto. Scientia \& Studia. v. 3, n. 4, p. 597-619, 2012.

SÃO PAULO. Secretaria de Educação. Coordenadoria de Estudos e Normas Pedagógicas. Proposta curricular para o ensino de Matemática do 1. ${ }^{\circ}$ grau. 4a. ed. São Paulo: SE/CENP, 1991.

VOGELMANN, E. P. A arte de ensinar e construir o conhecimento. São Paulo: Saraiva, 2011. 